\title{
Is Surgery a Good Choice for Patients over 100 Years with Hip Fracture?
}

\author{
Bogdan Deleanu1,2, Radu Prejbeanu1,2, Dinu Vermesan1,2, Lucian Honcea ${ }^{1}$, Cristina Nuta ${ }^{3}$, \\ Vlad Predescu ${ }^{4}$ \\ ${ }^{1}$ Orthopedics and Traumatology Clinic, Emergency Clinical County Hospital, Timisoara, Romania \\ ${ }^{2}$ Victor Babes University of Medicine and Pharmacy, Timisoara, Romania \\ ${ }^{3}$ Orthopedics Functional Recovery Compartment, Emergency Clinical County Hospital, Timisoara, Romania \\ ${ }^{4}$ St. Pantelimon Emergency Hospital, Carol Davila University of Medicine and Pharmacy, Bucharest, Romania \\ Email: ${ }^{*}$ lucianhoncea@gmail.com
}

Received 24 June 2015; accepted 18 August 2015; published 21 August 2015

Copyright (C) 2015 by authors and Scientific Research Publishing Inc.

This work is licensed under the Creative Commons Attribution International License (CC BY).

http://creativecommons.org/licenses/by/4.0/

\section{(c) (i) Open Access}

\begin{abstract}
Introduction: Elderly patients represent a difficult category of surgical candidates for orthopedic surgery because they have multiple associated diseases and a high degree of osteoporosis. Presentation of Case: We present the case of a 103 years old woman with a pertrohanteric hip fracture treated successfully using a $135^{\circ}$ dynamic hip screw. Discussion: There are many discussions about this kind of patients regarding postoperative complications, duration of hospitalization, stage of recovery and the patient's status at discharge. Conclusion: We conclude that surgery may benefit patients who are over 100 year-old.
\end{abstract}

Keywords

Osteoporosis, Age, Rehabilitation, Complications

\section{Introduction}

Hip fractures are very common in the elderly due to osteoporosis and multiple associated diseases. These fractures increase the risk of morbidity and mortality in this group of persons. A very important thing is the ASA classification which shows an evaluation of the patient's preoperative physical status [1]. There is an important correlation between ASA class and morbidity. We report a case of a pertrohanteric fracture in a patient very elderly.

*Corresponding author.

How to cite this paper: Deleanu, B., Prejbeanu, R., Vermesan, D., Honcea, L., Nuta, C. and Predescu, V. (2015) Is Surgery a Good Choice for Patients over 100 Years with Hip Fracture? Case Reports in Clinical Medicine, 4, $280-283$.

http://dx.doi.org/10.4236/crcm.2015.48056 


\section{Case Presentation}

We are about to discuss the case of a 103 years old female patient who presented to our Emergency Department with a severe pain in the left hip and inability to walk. The patient has multiple cardiac diseases like hypertension III degree, ischemic heart disease and osteoporosis, diabetes and no history of surgery. We concluded that according to ASA classification this patient is in ASA class III. A pelvic radiograph showed pertrohanteric fracture on left hip Evans II classification (Figure 1). She underwent open reduction and internal fixation of the left hip with a $135^{\circ}$ dynamic hip screw (Figure 2).

Postoperatively she stayed 14 days in the hospital and the hip pain significantly improved. Second day postoperative was initiated a recovery plan, including placing on bedside. Partial weight bearing on the left was initiated on the third day postoperative and maintained for the first 6 weeks. At 45 days the radiographs showed no loss of fixation and the patient walked with walker suport and the HHS (Harris Hip Score) was 66. At 4 months the radiographs showed union of the left hip fracture and the patient walked with a cane and the HHS was 74 . The HHS (Harris Hip Score) was 78 at one year, growth potential in the coming months, which we consider a good score for patient age.

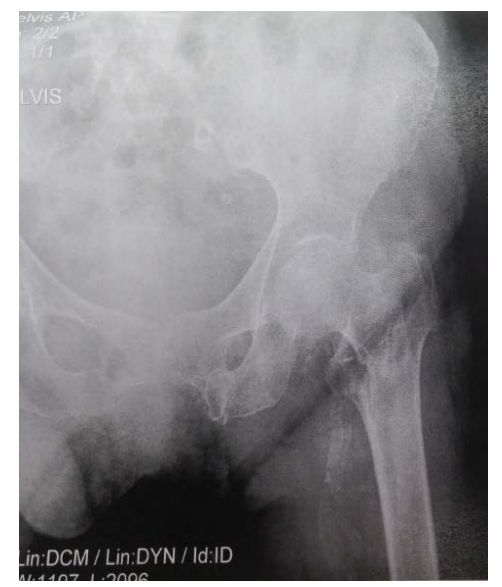

Figure 1. Preoperative radiograph.

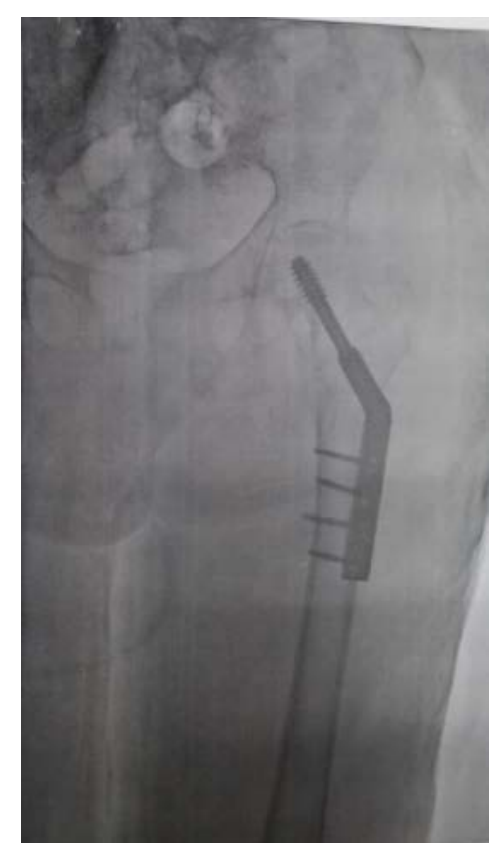

Figure 2. Postoperative radiograph. 


\section{Discussion}

Ridge et al. [2] demonstrated in a cohort study on 100 patients that there is no significant difference in tolerating the hip fracture surgery between population over 90 years and younger population. Some studies revealed that surgery followed by rehabilitation is recommended in patients over 90 years with hip fracture [3] [4].

Many studies have concentrated on factors that lead to postoperative complications and factors that affecting recovery of elderly patients after hip fracture [5] [6].

Duration of hospitalization is higher in older patients than in younger patients after hip fracture surgery [5]. Due to multiple diseases associated the patients over 90 years have a good chance to die during hospitalization [3]-[7].

The most important thing after hip fractures surgery is the patient's stage of recovery. In this stage of recovery some patients were able to walk without aid and were independents, some went with support (with a cane or a walker) and a small percentage of them were bedridden [8]. Ishida et al. [9] revealed that $45 \%$ of patients 90 years and older were able to walk without aid.

The patient's status at discharge, after surgery and rehabilitation treatment is also important. The patients over 90 years have significant chances to have a decrease in their basic activities of daily living status, because some patients never recover the pre-injury functional level [5] [10]. Arinzon et al. [11] sugested that average length of stay for rehabilitation was significantly higher in elderly patients.

\section{Conclusion}

In our opinion at this age we required surgical treatment if the patient walked before fall to avoid many complications like: thromboembolism, decompensation of pre-existing diseases, bedsores, urinary tract infection and pneumonia.

\section{References}

[1] Fitz-Henry, J. (2011) The ASA Classification and Peri-Operative Risk. Annals of the Royal College of Surgeons of England, 93, 185-187. http://dx.doi.org/10.1308/rcsann.2011.93.3.185a

[2] Ridge, C., Kearns, S., Cahill, K., Moroney, P., Kelly, E., O’Rourke, K., Dudeney, S., Hurson, B. and Quinlan, W. (2005) Morbidity and Mortality Following Hip Fracture in over 90's: A Cohort Study. Journal of Bone and Joint Surgery, 87-B, 264.

[3] Formiga, F., Lopez-Soto, A. and Sacanella, E. (2003) Mortality and Morbidity in Nonagenarian Patients Following Hip Fracture Surgery. Gerontology, 49, 41-45. http://dx.doi.org/10.1159/000066501

[4] Shah, M.R., Aharonoff, G.B., Wolinsky, P., Zuckerman, J.D. and Koval, K.J. (2001) Outcome after Hip Fracture in Individuals Ninety Years of Age and Older. Journal of Orthopaedic Trauma, 15, 34-39. http://dx.doi.org/10.1097/00005131-200101000-00007

[5] Kadowaki, M., Kono, M., Nishiguchi, K., Kakimaru, H. and Uchio, Y. (2012) Mortality in Patients with Hip Fracture Aged over 90 Years: A Report from a Progressively Aging Island. Archives of Gerontology and Geriatrics, 54, e113e117. http://dx.doi.org/10.1016/j.archger.2011.10.003

[6] Holt, G., Smith, R., Duncan, K., Hutchison, J.D. and Gregori, A. (2008) Outcome after Surgery for the Treatment of Hip Fracture in the Extremely Elderly. Journal of Bone and Joint Surgery, 90, 1899-1905. http://dx.doi.org/10.2106/JBJS.G.00883

[7] Giaquinto, S., Majolo, I., Palma, E., Roncacci, S., Sciarpa, A. and Vittoria, E. (2000) Very Old People Can Have Favorable Outcome after Hip Fracture: 58 Patients Referred to Rehabilitation. Archives of Gerontology and Geriatric, 31, 13-18. http://dx.doi.org/10.1016/S0167-4943(00)00061-3

[8] Intiso, D., Di Rienzo, F., Grimaldi, G., Lombardi, T., Fiore, P., Maruzzi, G., Iarossi, A., Tolfa, M. and Pazienza, L. (2009) Survival and Functional Outcome in Patients 90 Years of Age or Older after Hip Fracture. Age Ageing, 38, 619622. http://dx.doi.org/10.1093/ageing/afp126

[9] Ishida, Y., Kawai, S. and Taguchi, T. (2005) Factors Affecting Ambulatory Status and Survival of Patients 90 Years and Older with Hip Fractures. Clinical Orthopaedics and Related Research, 436, 208-215. http://dx.doi.org/10.1097/01.blo.0000159156.40002.30

[10] Kauffman, T.L., Albright, L. and Wagner, C. (1987) Rehabilitation Outcomes after Hip Fracture in Persons 90 Years Old and Older. Archives of Physical Medicine and Rehabilitation, 68, 369-371. 
[11] Arinzon, Z., Fidelman, Z., Zuta, A., Peisakh, A. and Berner, Y.N. (2005) Functional Recovery after Hip Fracture in Old-Old Elderly Patients. Archives of Gerontology and Geriatrics, 40, 327-336.

http://dx.doi.org/10.1016/j.archger.2004.10.003 